\title{
Conquista e integración de la Gallaecia en el reino visigodo
}

\author{
Conquest and integration of Gallaecia into the Visigothic kingdom
}

Pablo Poveda Arias, pablo.poveda.arias@gmail.com, https://orcid.org/0000-0002-2691-7912, Universität Hamburg, Alemania

\begin{abstract}
Resumen
En los últimos años la historiografía ha prestado una enorme atención a la Gallaecia tardoantigua, lo que ha contribuido a un mejor conocimiento del desarrollo histórico de esta región. Sin embargo, restan aún muchísimos interrogantes en torno a numerosas problemáticas, en lo que sin duda influye el carácter lacónico de las fuentes. Este es el principal problema al que nos enfrentamos cuando intentamos aproximarnos al proceso de integración del antiguo reino suevo dentro del reino visigodo, producido entre finales del reinado de Leovigildo (569-586) y durante todo el reinado de Recaredo (586-601). Siendo conscientes de tales dificultades, es nuestro propósito a lo largo de las siguientes páginas abordar todo este proceso, ahondando en las circunstancias y motivaciones que llevaron a la conquista de la Gallaecia por los visigodos, así como en las estrategias empleadas por estos para lograr una integración efectiva y definitiva del territorio y su sociedad. Aquí pondremos el acento en la negociación entablada por el poder visigodo con las élites locales y regionales, cuya colaboración se tornaba imprescindible para un gobierno efectivo del desaparecido reino suevo. Para ello, nuestro análisis propone distinguir aquellas estrategias desplegadas sobre las élites seculares de aquellas otras empleadas sobre las jerarquías eclesiásticas galaicas, en particular sus obispos. En lo referido a las primeras, el carácter lacónico de las fuentes documentales nos forzará a recurrir a otro tipo de testimonios, como los ofrecidos por la numismática. No resulta mucho más halagüeño el panorama documental referido a la esfera eclesiástica. En general, nuestro conocimiento relativo a las relaciones entre el episcopado galaico y el poder central visigodo dependerá de la escasa información que nos aportan las suscripciones episcopales en el III Concilio de Toledo, entre otras pocas referencias indirectas.
\end{abstract}

Palabras clave. Hispania tardoantigua; monarquía visigoda; moneda; obispos; suevos; visigodos.

\begin{abstract}
Abastract
In recent years, historiography has paid a great deal of attention to Late Antique Gallaecia, which has contributed to a better understanding of the historical development of this region. However, there are still a lot of questions about many issues, which is undoubtedly influenced by the laconic nature of the sources. This is the main problem we face when trying to approach the process of integration of the former Suevic kingdom within the Visigothic kingdom, which took place between the end of the reign of Leovigild (569-586) and the entire reign of Reccared (586-601). Being aware of such difficulties, our aim within the following pages is to deal with this whole process, delving into the circumstances and motivations that led to the conquest of Gallaecia by the Visigoths, as well as the strategies employed to achieve an effective and definitive integration of the territory and its society. We will focus on the negotiations between the Visigothic power and the local and regional elites, whose collaboration was essential for the effective government of the disappeared Suevic kingdom. To this end, our analysis proposes to distinguish those strategies deployed on the secular elites from those employed on the north-western ecclesiastical hierarchies, in particular their bishops. As far as the former are concerned, the laconic nature of the documentary sources will force us to resort to other types of testimonies, such as those offered by numismatics. The documentary panorama concerning the ecclesiastical sphere is not much more favorable. In general, our knowledge of the relations between the north-western episcopate and the Visigothic central power will depend on the scarce information provided by the episcopal subscriptions at the III Council of Toledo, among a few other indirect references.
\end{abstract}

Key words. Late Antique Hispania; Visigothic Monarchy; currency; Bishops; Suevi; Visigoths.

Financiación: Este trabajo se ha desarrollado en el seno del Centro de Estudios Avanzados "RomanIslam - Center for Comparative Empire and Transcultural Studies", financiado por la Fundación Alemana de Investigación (Deutsche Forschungsgemeinschaft, DFG) y adscrito a la Universidad de Hamburgo, así como en el marco del Proyecto de Investigación HAR2016-76094, financiado por el Ministerio de Ciencia e Innovación. 
"Leouegildus rex Gallecias uastat, Audecanem regem comprehensum regno priuat, Sueuorum gentem, thesaurum et patriam in suam redigit potestatem et Gothorum prouinciam facit".

(Ioh. Bicl., Chron. 72)

\section{INTRODUCCIÓN}

Con estas palabras Juan de Bíclaro describe la conquista e integración del reino suevo en el regnum Gothorum, acaecidas en el año $585^{1}$. Tal y como recoge la entrada del biclarense, el rey visigodo Leovigildo (569-586) saqueó en una única expedición militar la Gallaecia, depuso al rey suevo Audeca y tomó el control del pueblo, el tesoro y el territorio de los suevos, haciendo del regnum Sueuum una provincia visigoda ${ }^{2}$. A la vista de las palabras del cronista, podríamos pensar que la integración del reino suevo se trató de un proceso fácil, derivado de la mera conquista militar. Por otro lado, la historiografía suele asumir que la conquista de este reino fue la consecuencia natural de un supuesto proceso de unificación política y territorial de la península ibérica impulsado por el visigodo Leovigildo (Reinhart 1944-1945: 98-99; Gibert, 1956; Reydellet, 1981: 521; Sayas Abengochea, 1988; Rus Rufino, 2015: 86-87). Tal visión deriva en este caso de una lectura confiada de la obra de Isidoro de Sevilla, quien en sus escritos históricos asocia el territorio hispano a los godos y alaba la supuesta unificación del mismo bajo dominación visigoda como si este hubiese sido su destino natural (Isid. Hisp., Chron. 416 ${ }^{\text {b; Hist. De laude }}$ Spaniae; 63). Sin embargo, tales ideas pecan de caer en exceso en la teleología, puesto que Isidoro escribió tales obras cuando los visigodos habían logrado conquistar la inmensa mayoría del espacio peninsular. En otras palabras, más que recoger los acontecimientos pasados de forma fehaciente, en realidad el hispalense habría estado describiendo y justificando la realidad en la que él vivía ${ }^{3}$. De hecho, la propia asociación de Hispania con el pueblo godo puede considerarse una construcción ideológica del propio Isidoro, ausente, por otro lado, en la crónica de Juan de Bíclaro (Bronisch, 2006; Wood, 2012; Deswarte, 2014: 69).

Dentro de este esquema, cabe la posibilidad de que la unificación política del conjunto de la península ibérica bajo el dominio godo no hubiese formado parte del proyecto político original de la monarquía visigoda (Poveda Arias, 2020), ni siquiera en tiempos de Leovigildo, y; por ende, podemos plantear la hipótesis

1. Sobre el fin del reino suevo: Díaz, 2011: 138-152.

2. Haciéndose también eco de la conquista del reino suevo, Isid. Hisp., Chron. 407; Hist. 49; 91.

3. En relación a este tema, hacemos propias las palabras de Isabel Velázquez (2003: 164): "the crucial issue is, most of all, whether the information those sources supply reflect real events or whether, on the contrary, the convey each chronicler's percepction of his or her personal reality". de que la conquista del reino suevo tampoco fue una idea que entrase en los planes iniciales del visigodo. A partir de aquí es nuestra intención ahondar, por un lado, en las circunstancias que motivaron la conquista del reino suevo, cuestionando la idea asumida por la historiografía de que formó parte de un programa político de largo alcance, y, por otro, en el proceso de integración política, social y religiosa del territorio y la sociedad galaicas en el reino visigodo. Trataremos así de buscar las implicaciones concretas de las palabras de biclarense con las que abrimos el trabajo, las cuales quizás simplifican en exceso unas dinámicas que, como veremos, fueron bastante más complejas. Al hilo de estas mismas, la historiografía suele presentar de forma diferenciada las dinámicas laicas y eclesiásticas de integración del reino suevo. Sin embargo, no se puede entender el proceso en cuestión sin atender y poner en relación las políticas emprendidas por los monarcas visigodos en una y otra esfera. Solo de esta manera podremos entenderlo en toda su complejidad.

\section{LA CONQUISTA VISIGODA DEL REINO SUE- VO: CIRCUNSTANCIAS Y MOTIVACIONES}

Entrando a analizar las circunstancias que llevaron a la conquista del reino suevo, sabemos que años antes de la acción militar del 585, concretamente en el 576, Leovigildo emprendió una ofensiva anterior que le llevó a enfrentarse directamente con el rey suevo Miro (570583) y sus tropas. La expedición se saldó con el triunfo del visigodo. Las hostilidades llegaron a su fin con la negociación de una paz propuesta por el rey suevo y que Leovigildo aceptó a cambio del pago de un tributo, del cual las fuentes no nos ofrecen mayor detalle (Ioh. Bicl., Chron. 39) $)^{4}$. El acuerdo debió de suponer el pago de este tributo a cambio de evitar más ataques visigodos al reino suevo ${ }^{5}$. Para los suevos, aunque el pago de este implicaba un alto dispendio económico, al menos de esta manera evitaban la violencia y la arbitrariedad que implicaban las acciones militares y los saqueos sobre su territorio (Sarti, 2018: 181-182). La eficacia del tributo para mantener alejado al enemigo es indudable, no teniendo constancia de nuevos ataques godos al reino suevo hasta pasados nueve años ${ }^{6}$.

En lo que respecta a los visigodos, ciertamente el cese de las hostilidades con los suevos no casa con una pretendida política de conquista de todo el espacio peninsular. Si este hubiese sido el caso, no se entiende que Leovigildo hubiese aceptado la tregua que le

4. Es posible que este tributo hubiese adquirido un carácter anual. Sobre las distintas modalidades de tributo: Reuter, 1985.

5. Algunos han propuesto que las negociaciones se saldaron también con la pérdida, en favor de los visigodos, de parte del territorio suevo. Barroso Cabrera et al., 2015: 67. Sin embargo, no hay datos que avalen tales suposiciones.

6. Sobre los efectos positivos del pago de tributo de guerra para la parte derrotada, Coupland, 1999. 
ofreció el rey Miro cuando claramente se encontraba en una posición de fuerza y podía haberse apoderado del espacio suevo sin problema alguno. El propio Isidoro de Sevilla, al describir a los suevos, desprecia sus capacidades defensivas (Isid. Hisp., Hist. 68), lo que hace más incomprensible si cabe el desinterés visigodo por conquistar el reino vecino si este hubiese sido el objetivo. Da la impresión de que, más que una intencionalidad expansiva, la expedición visigoda tuvo un carácter predatorio, esto es, pretendió ofrecer a los visigodos las oportunidades de obtención de un jugoso botín de guerra; una motivación que por otra parte pudo subyacer a todas las ofensivas militares de Leovigildo en la península ibérica hasta el estallido de la revuelta de su hijo Hermenegildo (Poveda Arias, 2020). El tributo ofrecido por Miro habría sido así un sustitutivo del botín, el cual Leovigildo aceptó de buen grado al ser unas riquezas que acababan directamente en las arcas regias. Aparte de este impacto económico, el tributo conseguido le habría reportado además un rédito político y simbólico al visigodo, al marcar una relación de dominación sobre el pueblo sometido a tributo sin las preocupaciones que conllevaba el gobierno directo del mismo (Halsall, 2018: 64). Al mismo tiempo, lograba la estabilización y pacificación de las fronteras noroccidentales ${ }^{7}$. Además, frente al botín de guerra, que exigía su reparto a las tropas, el monarca no tendría que responder ante su gente por el tributo negociado, pudiendo gestionarlo según sus intereses (Reuter, 1985: 78), de ahí que optase por aceptar la oferta de Miro en lugar de continuar con los saqueos.

La actitud de Leovigildo prueba que el enfrentamiento militar no tenía que ser necesariamente la vía preferente de relación de los gobernantes visigodos con las realidades políticas vecinas, sino que a veces los intereses regios pasaron por mantener un entendimiento pacífico con ellos. De este modo, había ocasiones en las cuales las pretensiones de la monarquía residían en subordinar los deseos de saqueo de su gente en favor de la diplomacia. En este contexto, el rey habría buscado, posiblemente desde el principio, establecer una relación estable de subordinación y de dominación sobre los suevos a través de la imposición de un régimen tributario (Reuter, 1985: 87; Halsall, 2018: 64). Observamos así que los beneficios políticos y económicos de la actividad militar no pasaban únicamente por la conquista, sino que muchas veces los gobernantes estimaron en la consecución de un botín de guerra en forma de bienes muebles o, en este caso, de un tributo el beneficio más conveniente de sus esfuerzos bélicos. Es de suponer que las tropas visigodas no habrían aceptado de buen grado la pérdida del reino suevo como fuente de botín, pero ahí radicaba la capacidad del propio Leovigildo de proveerlas de nuevos objetivos contra los cuales

\footnotetext{
7. Aplicado al caso franco, Keller, 2013: 319, 350, quien califica la imposición de un régimen tributario como una "modalité de gestion des marges du royaume".
}

dirigir los esfuerzos militares y satisfacer así la codicia de estas. Es así como entendemos la campaña que al año siguiente dirigió contra la Orospeda (Ioh. Bicl., Chron. 46) ${ }^{8}$.

El nuevo modelo de relación entre suevos y visigodos se mantuvo en vigor durante prácticamente una década. El cambio llegaría a partir de la revuelta del príncipe visigodo Hermenegildo y la alteración del panorama geopolítico que esta trajo consigo. Las fuentes reflejan la implicación de los suevos en el conflicto interno godo, concretamente en los enfrentamientos decisivos que tuvieron lugar en el entorno de la ciudad de Sevilla, pero resultan contradictorias a la hora de alinearlos a uno u otro bando. Mientras Gregorio de Tours los sitúa luchando en el bando del príncipe rebelde (Greg. Tur., DLH VI, 43) ${ }^{9}$, Juan de Bíclaro e Isidoro de Sevilla los colocan en las líneas de Leovigildo (Ioh. Bicl., Chron. 65; Isid. Hisp., Hist. 91), siendo esta la opción por la que nos inclinamos, fundamentalmente porque se tratan de los testimonios más cercanos a los hechos. De hecho, el autor hispalense vivió los acontecimientos en primera persona. De este modo, consideramos que la intervención de Miro en la guerra entre godos obedeció al régimen de dependencia que se fraguó años atrás con el pago deł tributo a los visigodos, y que habría hecho del rey suevo una suerte de cliente de Leovigildo, forzado en consecuencia a responder de forma efectiva a la llamada de este cuando se le requiriese (Ioh. Bicl., Chron. 65; Isid. Hisp., Hist. $91)^{10}$. Este régimen de relación tendría continuidad con el sucesor de Miro, su hijo Eborico, quien accedió al trono suevo después de que su padre cayese en el enfrentamiento contra Hermenegildo ${ }^{11}$. Aunque en este punto dependemos del testimonio lejano de Gregorio de Tours, Eborico logró cerrar un nuevo acuerdo con Leovigildo, presumiblemente en unos términos similares a los acordados en origen con Miro (Greg. Tur., DLH VI, 43).

Sin embargo, el reinado de Eborico estaría abocado a la brevedad. Al año de su ascenso al trono, fue destituido por el suevo Audeca, quien recluyó al aún joven rey en un monasterio y se desposó con la viuda de Miro, Sisegutia (Ioh. Bicl., Chron. 67; Greg. Tur., DLH VI,

8. Sobre la problemática que gira en torno a su localización: García Moreno, 2008: 78, n. 186; Vallejo Girvés, 2012: 230-231.

9. Aceptando esta posibilidad, Beltrán Torreira, 1989: 72; García Moreno, 2008: 120, 150-151, entre otros.

10. No descartamos, en la línea planteada por Pablo C. Díaz (2011: 149), que originalmente la intención de Miro fuera estar expectante al desarrollo de los acontecimientos antes de inclinarse definitivamente por un bando $u$ otro. Por su parte, Biagio Saitta (1979: 121) planteó como opción de consenso la idea de que en un principio Mirón luchó en favor del rebelde, pero en un momento dado se cambió de bando.

11. Gregorio de Tours entra de nuevo en contradicción con las fuentes hispanas, al señalar que Miro murió a su regreso a la Gallaecia. Greg. Tur., DLH VI, 43. 
43; Isid. Hisp., Hist. 92). El nuevo monarca justificó la usurpación de Eborico reclamando la recuperación de la plena soberanía sueva después de la sumisión de Miro y su hijo a los visigodos (Díaz, 2011: 151) ${ }^{12}$. Esto es, Audeca habría pretendido romper las relaciones de subordinación con el reino visigodo como una forma de diferenciarse de sus predecesores y marcar una línea propia de gobierno que lograse cohesionar a la aristocracia sueva en torno a su persona ${ }^{13}$. Además, a la hora de consumar la usurpación, se aprovechó de que Leovigildo se encontraba inmenso en el enfrentamiento contra su hijo, y que por tanto no podía acudir en auxilio de Eborico, al menos de forma inmediata ${ }^{14}$. Sin embargo, sofocada la revuelta, el visigodo se veía libre para dar respuesta por la vía armada a la usurpación de Audeca, aunque ahora sí que se decidió finalmente por la conquista del reino suevo (Ioh. Bicl., Chron. 72; Isid. Hisp., Chron. 407). En este cambio de parecer habrían influido quizás las intenciones del usurpador, con los potenciales problemas que ello podía acarrear a la parte visigoda $^{15}$. Es posible por tanto que el factor decisivo que condicionó el cambio de actitud de Leovigildo fuera la ruptura del status quo fijado en su día con Miro y que Eborico estuvo dispuesto a mantener y no un supuesto proyecto de unificación política de la península ibérica bajo soberanía visigoda. Concretamente, Leovigildo habría visto en Audeca un nuevo competidor en el escenario geopolítico y, por extensión, un objetivo a neutralizar ${ }^{16}$. Con esto queremos decir que Leovigildo únicamente se limitó a acabar con aquel actor político que en esos momentos rivalizaba de forma frontal con él y sus intereses, como medida preventiva a una posible escalada de poder del mismo.

Leovigildo se apoderó del reino suevo en un único movimiento militar (Ioh. Bicl., Chron. 72; Isid. Hisp., Chron. 407; Hist. 49; 92). Respecto a Audeca, sufrió un destino no muy diferente al de Eborico. En particular, fue tonsurado, se le forzó a entrar en el presbiterado y se le envió al exilio fuera del territorio suevo, concretamente a la lejana Pax Iulia (Beja, Portugal) (Ioh. Bicl.,

12. Las reivindicaciones de Audeca tienen un claro reflejo en las acuñaciones monetarias a su nombre. Grierson, 1962.

13. En caso de aceptar el pago de un tributo anual, debemos entender que la usurpación de Audeca trajo consigo el fin de tales reembolsos.

14. La crónica de Juan de Bíclaro sitúa la usurpación en las acciones de asedio de Leovigildo a la ciudad de Sevilla. Ioh. Bicl., Chron. 66-68.

15. Es posible que Audeca hubiese llegado incluso a cerrar una alianza con el merovingio Gontran. Greg. Tur., DLH VIII, 35. García Moreno, 2008: 169.

16. Se cumpliría aquí el principio antropológico de "exclusión competitiva": "the principle of competitive exclusion [...] states simply that two species occupying and exploiting the same portion of the habitat cannot coexist indefinitely. Sooner or later one of them will eliminate the other". Carneiro, 1978: 208.
Chron. 75; Isid. Hisp., Hist. 92 ${ }^{17}$. Estos movimientos habrían buscado, por un lado, inhabilitarle como rey $\mathrm{y}$, por otro, alejarlo todo lo posible de sus grupos políticos de apoyo. Con todo, su exilio se debió no tanto a un potencial regreso al trono suevo, puesto que se le incapacitó para tal, sino a evitar que pudiese confabular para promover a alguien afín a su persona ${ }^{18}$. Asimismo, el tesoro regio de los suevos fue tomado (Ioh. Bicl., Chron. 72). Tal y como han defendido distintos especialistas, de esta manera se privaba de forma simbólica a los suevos de su soberanía ${ }^{19}$. Sin embargo, es posible que las implicaciones de este movimiento hubiesen ido más allá de la mera esfera simbólica. Cabe la posibilidad de que el thesaurum no hubiese custodiado únicamente los bienes preciosos con los que se identificaba y se hacía representar la monarquía sueva, sino también la documentación que legitimaba los títulos de propiedad de su patrimonio fundiario, así como los registros de las donaciones hechas a las élites del reino con las que compraban su fidelidad ${ }^{20}$. El tesoro regio habría conformado así la parte física y material del patrimonio que gestionaba la monarquía sueva. De este modo, consideramos que con la privación de este también se estaba arrebatando a los suevos, y en particular a sus reyes, de sus bases materiales de poder, al tiempo que se obstaculizaba el éxito a todo potencial candidato a recuperar el trono. Creemos, por tanto, que el tesoro no tenía una capacidad de legitimación en sí mismo $^{21}$, sino que en realidad era el propio uso que se diera de él, en concreto a través de su redistribución a las élites, lo que de verdad dotaba a la monarquía de una legitimidad y reconocimientos propios por encima de otros agentes de poder. El tesoro tendría en consecuencia un cometido simbólico, como marcador de la soberanía regia, en tanto en cuanto este viniera asociado a un papel funcional mucho más relevante en la construcción de una supremacía fáctica por encima del conjunto de la sociedad y, en especial, de las élites a través de los vínculos personales que se forjaron con su redistribución ${ }^{22}$. En definitiva, la toma del tesoro

17. Sobre la elección de este destino, Salinero-Sánchez, 2020: 91-93.

18. Sobre su exilio, Vallejo Girvés, 2003; Frighetto, 2015.

19. Algunos estudiosos del período remarcan este papel simbólico del tesoro regio como instrumento de legitimación de los monarcas. Díaz y Valverde Castro, 2000: 68-71; Arce, 2011; Díaz, 2011, entre otros.

20. Sobre la composición del tesoro regio, Hardt, 1998. Ante la falta de información para el caso suevo, la Galia merovingia nos permite ejemplificar la argumentación aquí defendida: Greg. Tur., DLH IV, 12; X, 9; X, 19. Magnou-Nortier, 1996: 322 . Sobre la variedad de documentos que podían guardarse en el tesoro regio y su gestión, Dumézil, 2015.

21. En este sentido, nos hacemos eco de las palabras de Luis A. García Moreno (1974a: 63, n. 239) al afirmar que "la posesión del tesoro en sí no suponía la investidura de la realeza".

22. Tal y como afirma Hans-J. Schmidt (2003: 12): "la matière du trésor est engagée pour gagner une quantité de ressources humaines". Aunque aplicado a otra casuística, remarca esta 
suevo constituyó en cierta manera una medida preventiva para evitar que en un momento dado un personaje determinado con aspiraciones regias pudiese utilizarlo para atraerse una amplia masa de apoyos que pudiera en un momento dado competir y amenazar el propio liderazgo regio.

\section{LA INTEGRACIÓN DEL ESPACIO GALAICO EN EL REINO VISIGODO I: LA VERTIENTE SE- CULAR}

Aparte de privar a Audeca del trono y de apoderarse del tesoro suevo, el biclarense afirma que Leovigildo absorbió el pueblo y el territorio de los suevos, cerrando así su relato sobre la conquista de la Gallaecia. Sin embargo, la simple conquista y absorción del desaparecido regnum no bastaban para asegurarse un control territorial y social de larga duración. Prueba de ello, sabemos que al poco tiempo de la conquista estalló una revuelta en contra de la dominación visigoda, una tentativa encabezada por un tal Malarico que fue sofocada de forma inmediata por los duces visigodos y que concluyó con el apresamiento del "tirano" (Ioh. Bicl., Chron., 76) ${ }^{23}$. Es cierto que después de esta tentativa no volvemos a tener referencia alguna a ninguna otra revuelta, dando así prueba del éxito visigodo a la hora de integrar la Gallaecia ${ }^{24}$. Es obvio que el intento frustrado de recuperar la independencia y el propio apresamiento de Malarico mandaron un mensaje contundente para evitar en el corto plazo futuros levantamientos, pero no fue ni mucho menos la clave del éxito visigodo al implantar su poder en este territorio. Cabe por tanto preguntarse por los mecanismos desplegados para ello.

La misma noticia que nos habla del intento de Malarico nos ofrece algunas pistas sobre los primeros movimientos de Leovigildo para controlar sus nuevos territorios. Nos referimos en particular a la alusión que se hace a los duces visigodos, sobre quienes se depositó la responsabilidad de reprimir la revuelta. Es de suponer que estos duces, cuya función principal era dirigir a las tropas (Martin, 2003: 168), fueron radicados en la Gallaecia junto a sus contingentes militares en el momento de la conquista del reino suevo con

función del tesoro regio: Grierson, 1959: 138. No negamos que con el tiempo el tesoro perdiese importancia simbólica en favor de otros marcadores del poder regio y de legimitimidad del mismo. Díaz y Valverde Castro, 2000: 69-71.

23. Sobre esta revuelta, Martin, 2003: 97.

24. Es de suponer que buena parte de los esfuerzos integradores se dieron a partir del reinado de Recaredo, puesto que la revuelta de Malarico tuvo lugar pocos meses antes de la muerte de Leovigildo. Esto concuerda además con la línea general que se percibe en el reinado de Recaredo, el cual, frente a la fase anterior, se centró más en asegurar un control de largo recorrido para los territorios conquistados por su padre que en ampliar las fronteras del reino (Isid. Hisp., Hist. 55; Díaz, 2008: 360). el mandato de mantener bajo control por la vía de la intimidación a la región y de reprimir, como ocurrió, cualquier tentativa de resistencia al poder visigodo ${ }^{25}$. No descartamos que, además, estos duces hubiesen tenido delegadas otras funciones extra-militares, actuando como líderes últimos de la región en ausencia del rey y en consecuencia como nudo de comunicación directo entre las élites suevo-galaicas y el poder visigodo $^{26}$. Esto es, al mismo tiempo que se mantenía la vía de la intimidación, estos mismos agentes militares habrían tenido la para nada desdeñable función de negociar con las élites autóctonas para integrar y gobernar de forma efectiva la región. Sin duda, esta última tarea habría estado delegada en los propios agentes que el rey destinaba a los distintos territorios del reino, pero también, y quizás más importante, en las propias élites locales que se integraron dentro del régimen visigodo y de las redes de servicio al rey ${ }^{27}$. En consecuencia, como ocurría para el conjunto del reino, para imponer una dominación efectiva y de largo recorrido se requería el apoyo y la colaboración de las élites laicas y eclesiásticas galaicas, que eran las que al fin y al cabo tendrían que seguir gobernando in situ, ahora en nombre del monarca visigodo ${ }^{28}$.

Pero ¿cómo se lograba la colaboración de unas élites que habían sido derrotadas y conquistadas? En primer lugar, el poder visigodo se habría esforzado por transmitir una imagen de estabilidad para las élites, esto es, que su situación se alterase lo menos posible a pesar de la conquista. Es así como entendemos, aparte de por una cuestión de pragmatismo, la preservación de las estructuras políticas, sociales y territoriales suevas, aunque ahora integradas y controladas por la monarquía visigoda. Esta cuestión ha sido trabajada en profundidad por Pablo C. Díaz (1997: 265), quien presenta un balance de la situación en los siguientes términos:

25. Sobre la naturaleza militar de su misión, Díaz, 2019: 87. Apostando también por una ocupación militar en tiempos de Leovigildo, Barroso Cabrera et al., 2015: 69.

26. Sabemos, por ejemplo, que poco después, reinando ya Recaredo, el dux Claudio estaba ejerciendo funciones judiciales en la ciudad de Mérida (VSPE, V, 10, 27-33; V, 11, 49-55). Tales funciones habrían tenido originalmente un carácter informal, recibiendo con el tiempo una sanción en la legislación civil (Poveda Arias, 2021). Negando tales funciones extra-militares en estos momentos tan tempranos, García Moreno, 1974a: 120-121; Díaz, 2019.

27. Un modelo similar ha sido perfilado para el reino astur-leonés posterior. Carvajal Castro, 2017: 183. Véase también Pachá, 2019: 115 .

28. Haciéndonos eco de las palabras de Maurice Godelier (1989 [1984]: 186), "para imponer y mantener en el poder a una parte de la sociedad [...], la represión cuenta menos que la adhesión, la violencia física o psicológica menos que la convicción del pensamiento que lleva consigo la adhesión de la voluntad, la aceptación sino la cooperación de los dominados". 
"a conquista visigoda de Gallaecia non supuxo ningún proceso de represión ou violencia sobre a provincia; os seus límites, as súas xentes e as súas estructuras organizativas van ser integradas sen alteración. A dominación visigoda acepta un estado de cousas e na medida que funciona non busca alternativas" ${ }^{29}$.

Dicho principio tiene una correspondencia en el plano económico, puesto que los sistemas de producción y circulación de bienes controlados por las élites, aunque bajo la supervisión última de la monarquía, tendrán una clara continuidad en época visigoda. De hecho, al hilo de esto se ha planteado que uno de los mecanismos regios para asegurarse la colaboración de las élites galaicas fue la delegación de derechos en la explotación de recursos, en especial metalíferos (Sánchez Pardo, 2014). El poder visigodo optó por tanto por recurrir a una estrategia conciliadora, que evitase las tensiones a corto y largo plazo. Es quizás así como se puede explicar que Leovigildo hubiese optado por condenas de prisión para Audeca y Malarico y no por medidas más drásticas, como la ejecución, que habrían alimentado los rencores. En un sentido similar podríamos entender la perpetuación de una identidad propia para la región a lo largo de todo el período visigodo. De este modo, el antiguo territorio suevo siempre permaneció en cierta manera en la memoria colectiva como una realidad territorial diferenciada del resto de Hispania, siendo así el reino visigodo la suma de Hispania, Gallia y Gallaecia (Díaz, 2019: 83) . $^{30}$

Con todo, aunque ayudaron, tales acciones no explican por sí solas cómo los reyes visigodos lograron la adhesión y colaboración de las élites suevo-galaicas. Aquí creemos que la clave residió en la integración de estas, o al menos de buena parte de ellas, en las redes de fidelidad de los monarcas visigodos (Castellanos y Martín Viso, 2005). Es posible que en este proceso los visigodos hubiesen encontrado una cierta predisposición de estas élites de acercarse al nuevo poder y de aceptar las condiciones propuestas con el fin de mantener su privilegiada posición. Algunos incluso habrían visto en la nueva situación de dominación goda una oportunidad para medrar y dar satisfacción a sus intereses personales (Kulikowski, 2012: 47). Especialmente patente se haría este modelo en aquellos casos en los que estos individuos se encontrasen en una posición comprometida en el seno de sus respectivas comunidades o no hubiesen gozado del favor de los gobernantes

29. Insiste en la misma idea en: Díaz, 2004: 373; 2011: 202. En una línea similar, pero aplicado únicamente al territorio meseteño que previamente había formado parte del reino suevo, Martín Viso, 2011: 234. A modo de comparación, la monarquía merovingia actuó de forma similar en el momento de integrar al reino burgundio dentro del regnum Francorum. Kaiser, 2003: 91-95.

30. Por su parte, Céline Martin (2003: 85) ve en estas formulaciones un cliché retórico de las fuentes. suevos $^{31}$. Estimamos así que, en líneas generales, las élites locales suevas y galaicas habrían buscado adherirse al nuevo régimen más que entrar en confrontación con él (Fernández, 2017: 188). Ello no tiene que implicar que el status quo previo se mantuviese plenamente bajo la soberanía visigoda. Debemos de asumir la idea que cualquier proceso de conquista viene acompañado por una reestructuración de las élites, eso sí, en proporciones variables (Bougard et al., 2013: 1106-1107). La cuestión en este caso es que esa proporción tratara de ser lo menos traumática posible. Por otro lado, debemos suponer también la existencia entre determinados sectores poderosos de la sociedad suevo-galaica de ciertos recelos a la hora de aceptar la nueva situación, lo que requirió aplicar unas mayores dosis de persuasión. Es quizás en este sentido en el que podemos entender algunas acuñaciones monetarias visigodas en la región en tiempos de Leovigildo y Recaredo, concretamente en las cecas de Bergancia, Bracara, Calapa, Luco, Portocale, Pincia, Senabria, Tornio y Tude, donde se remarca la victoria visigoda con la leyenda victor o victoria en contraposición a aquellas otras emitidas en la región con la leyenda convencional pius, la cual, dentro de este esquema explicativo, se habría dado en comunidades que desde el principio mostraron una mayor acogida a la dominación visigoda ${ }^{32}$.

Al final, poder central y poderes locales habrían entablado unas relaciones de interdependencia, puesto que el primero requería de los segundos para proyectar su soberanía en las localidades, mientras que las élites de cada comunidad necesitaban el sostén de la monarquía para perpetuar su poder ${ }^{33}$. Estamos así ante un modelo de relación basado en la reciprocidad, aunque asimétrica, en el cual ambos recibían algo a cambio ${ }^{34}$. Es cierto que, en calidad de derrotados, el margen de negociación de las élites suevas y galaicas habría sido menor, pero no por ello su importancia dejó de ser central. Vemos así que, en lo que recuerda a los propios mecanismos que los suevos utilizaron para implantarse en el territorio galaico, los visigodos buscaron

31. Tal y como defiende Guy Halsall (1998: 143) para la realidad franca: "powerful people want their local preeminence to be independent of the royal (or similar) court, but it may well not be posible to establish local power without 'central government' legitimation".

32. Sobre estas acuñaciones y su problemática, Pliego, 2012: 81; Kurt, 2020: 212-214. En lo que respecta a esta distinción en las leyendas, Osland, 2011: 81-82. Retomaremos el tema de las acuñaciones monetarias infra.

33. "Kings and elites were bound together because both lacked an institutional basis for the exercise of local power, and so both dominated socially rather than administratively, and exercised their domination on an extensive stage that they shared" (Innes, 2000: 261).

34. De nuevo, las palabras de Maurice Godelier (1989: 192) y su perspectiva antropológica nos permiten ilustrar esta idea: "para perdurar, todo poder dominante, incluso el nacido de la violencia, debe adoptar la forma de un intercambio de servicios". 
una acomodación entre sus propios intereses y aquellos de las propias élites suevas y galaicas para asegurar su colaboración (Díaz, 2011: 153-206; 2015: 218).

En lo que respecta a los mecanismos empleados por el poder visigodo para lograr la adhesión de las élites suevo-galaicas, las fuentes ofrecen poco más que nos pueda ser de utilidad. Para obtener más pistas tenemos que recurrir a otras evidencias, siendo este el caso de la moneda. Gracias al numerario visigodo conservado, sabemos que ya en tiempos de Leovigildo, pero en especial a partir del reinado de Recaredo (586-601), se acuñó moneda a su nombre en diversos lugares de la Gallaecia, tanto en las ciudades como en los horizontes rurales ${ }^{35}$, dando lugar a la mayor concentración regional de cecas de todo el reino (Miles, 1952: 125-146; Díaz, 2004: 67; Pliego, 2012) 36 $^{36}$. Debemos suponer que estas se correspondían con aquellos centros territoriales de control adscrito al poder central y desde los cuales este habría proyectado la soberanía regia sobre la región, en lo que consideramos una estrategia más dirigida a integrar el espacio galaico en la esfera política visigoda (Martín Viso, 2015: 107). Tal y como ha demostrado Pablo C. Díaz (2004) de forma convincente respecto a este tema, tales cecas se habrían correspondido con los centros administrativos del antiguo reino suevo, en la mayoría de los cuales se había acuñado previamente moneda sueva, hecho que, según el autor, explicaría la excepcional proliferación de centros de acuñación en la fase visigoda ${ }^{37}$. Este mismo especialista planteó, a nuestro modo de ver de forma bastante acertada, que la elección de estos lugares vino determinada por su papel previo como posibles centros de fiscalidad y de administración de justicia (Díaz, 1997: 265; 2011: 202). Para demostrar su teoría, observa que un total de 40 cecas visigodas se correspondían con las iglesias recogidas en el denominado Parrochiale Sueuum (Díaz, 2011: $199)^{38}$. En este modo de actuar influyó sin duda alguna la fragmentación territorial del propio territorio galaico, la falta de implantación en el mismo de una densa red urbana en favor de centros secundarios o semi-urbanos y la progresiva poli-nucleación o dispersión social

35. Sobre el reinado del primero, únicamente tenemos constancia de 4 cecas de un total de 20 o 22 , mientras que del reinado de Recaredo sabemos que acuñó moneda en al menos 20/22 cecas galaicas de un total de 46/48 (Osland, 2011: 78). Al menos en el plano secular, Leovigildo debió mostrar mayor preocupación en los últimos años de su reinado por la integración del mediodía hispano. A ello apunta indirectamente el hecho de que la práctica totalidad de monedas acuñadas bajo su nombre se sitúen en el sudoeste peninsular (Retamero, 2001: 122).

36. Esta proliferación de cecas contrasta, sin embargo, con la baja proporción numerario disponible de las mismas, que constituye apenas entre un 4 y un $6 \%$ del total disponible (Díaz, 2004: 70, n. 16; Pliego, 2012: 76-79).

37. Defendiendo este punto de vista, Martin, 2003: 46.

38. En este caso, tales iglesias estarían reflejando, en palabras del mismo autor, "una adaptación al poblamiento y organización del campo" (Díaz, 1998: 44). en pequeños centros de población (Díaz, 2015: 94) ${ }^{39}$. Observamos, por tanto, que el poder visigodo mostró una enorme capacidad de adaptación a las particularidades regionales de la Gallaecia, un factor más que puede explicar su éxito a la hora de integrar de forma efectiva la región (Martín Viso, 2011: 216, 239).

Respecto al papel desempeñado por las monedas que se acuñaron en las cecas galaicas, estas suponen una prueba de la extensión de la red de fidelidades, voluntaria o forzada, de los monarcas visigodos sobre la región, y en particular sobre sus élites. En particular, consideramos que la moneda se convirtió en un instrumento de primer orden para fijar lealtades en torno al monarca visigodo. Tal y como ha expuesto recientemente Iñaki Martín Viso (2015: 102), "la moneda es un instrumento creado por un poder, que al mismo tiempo representa su autoridad y también la aceptación de su legitimidad por parte de quien utiliza esa moneda, avalada por el poder emisor". Menos certezas tenemos sobre los procedimientos concretos en los que la moneda adquiría ese papel central ${ }^{40}$. Una línea mayoritaria de la historiografía, y de la cual el citado Iñaki Martín Viso (2008a; 2008b; 2011; 2013; 2015) constituye actualmente su principal representante, le atribuye a la moneda visigoda una funcionalidad fundamentalmente fiscal ${ }^{41}$. Sin embargo, no es la única posibilidad interpretativa. En lo referido a la Gallaecia, se ha propuesto la sugerente hipótesis de que las monedas hicieron el papel de "regalos" de la monarquía a las élites suevo-galaicas (Pliego, 2012: 99) ${ }^{42}$. Uno y otro modelo se han presentado como contrapuestos, pero esta perspectiva cambia si le atribuimos un papel multifuncional a la moneda, el cual se ha planteado para otras realidades políticas del momento, pero no se suele asumir con igual convencimiento para el caso visigodo $^{43}$. Dentro de este esquema, la moneda pudo

39. Atendiendo a las palabras de este autor, "esta proliferación de cecas tiene que entenderse en su contexto, que no es necesariamente el del reino visigodo sino el de la herencia institucional que la provincia visigoda de Gallaecia heredó de su pasado suevo" (Díaz, 2011: 199). Sobre la pérdida de importancia del elemento urbano en la región, véase también: Martin, 2003: 53.

40. Sobre la función que podía desempeñar la moneda en el contexto galaico, ofrecen un estado de la cuestión bastante detallado: Díaz, 2004; Kurt, 2020: 211-220.

41. Defendiendo también una funcionalidad fiscal para la moneda visigoda, García Moreno, 1982; Barceló, 1999; Kurt, 2009; Retamero, 2011; Osland, 2011, entre otros.

42. Sin embargo, no aporta una argumentación detallada para defender su postura. En un plano general, considera -aunque no de forma exclusiva - también las monedas como parte integrante de los "regalos": Naismith, 2014a: 21-23.

43. Rory Naismith (2014b) planteó esta multifuncionalidad para la moneda merovingia, no así para la visigoda, la cual circunscribe a un ámbito de circulación fiscal. Véase también Naismith, 2014a. Aceptando la multifuncionalidad del tremis visigodo, Metcalf, 1999; Doménech Belda, 2014: 30, aunque asume un uso preferentemente fiscal. Recientemente 
haber servido también como pago por determinados servicios (Pliego, 2009: 226-227) ${ }^{44}$, así como instrumento de conmemoración y propaganda (Martin, 2003: 270-271; Vallejo Girvés, 2012: 323-326) ${ }^{45}$, aunque en este último caso es cierto que se habría tratado de una funcionalidad de corte secundario, complementario a otras (Kurt, 2020: 174). Por tanto, esta comprensión multifuncional de la moneda visigoda puede ayudar a entender mejor la enorme variabilidad geográfica de situaciones de circulación y de emisión monetarias. Aquí, sin embargo, pretendemos incidir en su funcionalidad como "regalos".

La entrega de "regalos" fue uno de los principales instrumentos empleados por la monarquía a la hora de construir vínculos de fidelidad con su persona. Especialmente importantes habrían sido aquellos que hubiesen tomado la forma de tierras (Barbero y Vigil, 1978; Díaz, 2012), pero no podemos desdeñar el papel de las riquezas muebles, igualmente importantes en la reproducción social de las élites. Estas habrían funcionado como bienes de prestigio que infundían a su posesor un plus de capital simbólico, siendo especialmente valorados aquellos obtenidos de manos o en nombre del monarca (Hardt, 1998: 267; Le Jan, 2010: 366-368; Bougard et al., 2013: 1089-1091). La moneda de oro no dejaba de ser un bien de prestigio y distinción (Pliego, 2009: 226-229; Martín Viso, 2011: 247-248) ${ }^{46}$, por lo que se nos estima lógico que hubiese desempeñado un papel importante en la redistribución de riquezas por parte de la monarquía visigoda. De hecho, creemos que la definición del sistema monetario basado en el oro y no en la plata habría obedecido, no tanto a un interés tributario, el cual no negamos, sino precisamente a esta funcionalidad que se le quería infundir a la moneda como bien de prestigio. Como marcadores de distinción, las monedas se habrían exhibido como

se ha planteado este esquema multifuncional de la moneda visigoda, pero sin valorar su importancia como "regalos". Kurt, 2020.

44. En este esquema multifuncional de la moneda también encajaría su uso para hacer frente al sufragio de expediciones militares, pudiendo ser esta en parte la explicación de acuñaciones monetarias en zonas fronterizas y de forma coetánea a campañas militares. Véase García Moreno, 1982: 339-341; Barbero y Vigil, 2012 [1970]: 79-81; Kurt, 2020: 191-220.

45. Rechazamos, sin embargo, que la moneda visigoda hubiese desempeñado una función económica o comercial, al parecernos poco funcional como instrumento de transacción. Cf. Barril i Altet, 1976: 67-77; Metcalf, 1999; Kurt, 2020: 188-189.

46. Este papel de la moneda visigoda puede explicar el hecho de que la mayor parte del numerario haya sido hallado en contextos de atesoramiento y, por tanto, su escasa circulación. Poniendo de manifiesto esta escasa circulación del numerario visigodo, Pliego, 2009: 230. De hecho, parece ser que a lo largo de todo el período visigodo las emisiones regias habrían gozado de una credibilidad y de un valor similares y perdurables, independientemente de la calidad del numerario en circulación. Retamero, 2011: 210-220. bienes de ostentación en los espacios de sociabilidad, como por ejemplo en las iglesias ${ }^{47}$. Así entendemos, aunque en otro contexto geográfico, el hallazgo de monedas asociadas al complejo episcopal del yacimiento de El Tolmo de Minateda ${ }^{48}$. Por consiguiente, la posesión del numerario oficial habría servido a su portador para remarcar una posición social destacada y su vínculo con el poder central. Por su parte, el monarca habría salido igualmente beneficiado como autoridad emisora que ve legitimada y reconocida su soberanía por parte de aquel que acepta ese numerario. Por otro lado, la moneda, al mismo tiempo que simbolizaba una especial vinculación al rey visigodo y al sistema que este representaba, también habría servido de recordatorio de la conquista y, por tanto, de a quién le debían las élites el mantenimiento de su estatus social. Aunque intrínsecamente la concesión de "regalos" implicase una relación de subordinación y de dependencia del beneficiario frente al monarca, en un principio el receptor de las monedas no lo vería como tal, sino como una seña de distinción social con la que poder sobresalir en el contexto de competencia social al que debían hacer frente en el seno de sus respectivas comunidades.

Para reforzar nuestra postura, planteamos tres argumentos que pueden ayudar a entender en mayor medida esta inclinación por la moneda como mecanismo de dominación sobre las élites galaicas. Por un lado, tendríamos el argumento fundiario. Ciertamente, la monarquía visigoda no habría dispuesto de una masa fiscal importante en la Gallaecia como para hacer frente a una política sistemática de donaciones de tierras a las élites de la zona. Es obvio que Leovigildo y Recaredo absorbieron las tierras fiscales del reino suevo, pero estas habrían sido empleadas sobre todo, por un lado, como remuneración a sus propias tropas por la conquista $\mathrm{y}$, por otro, habrían quedado en posesión de la monarquía para proyectar y reproducir la soberanía regia en la zona. Por consiguiente, el margen de maniobra era bastante pequeño, siendo el "regalo" en forma de bienes preciosos, en este caso en moneda, una de las pocas vías a disposición de los reyes visigodas para asegurarse en la región unas redes de fidelidad más o menos fiables. Asimismo, en favor de nuestra postura, tendríamos también un argumento de tipo ideológico. Si la acuñación monetaria hubiera tenido una funcionalidad exclusivamente fiscal y, por tanto, destinada a acabar en Toledo, no se comprende que algunas de las monedas allí acuñadas fuesen impresas en tiempos de

47. Es quizás en este sentido en el que podríamos entender la conversión ocasional que vemos de tremises en objetos ornamentales o su aparición en contextos funerarios. Véase la casuística recogida en: Martín Viso, 2015. Al fin y al cabo, si tomamos como válidos los postulados de Guy Halsall (2018: 59): "people wore their riches".

48. Por su parte, Carolina Doménech Belda (2013: 30), considera que las monedas en cuestión confirman la funcionalidad fiscal de la misma. 
Leovigildo, pero especialmente durante de Recaredo ${ }^{49}$, con mensajes propagandísticos de las victorias visigodas (Pliego, 2012: 81, 96) ${ }^{50}$. Este modo de proceder únicamente habría tenido sentido si las monedas en cuestión hubiesen sido concebidas para circular en una dirección centrífuga, fuera de Toledo. Además, sabemos que, a nivel global, en torno al 50\% de los hallazgos individuales de moneda se han producido en un radio de $200 \mathrm{~km}$ de sus cecas y, por tanto, no era una moneda destinada a acabar en el centro del poder político visigodo (Kurt, 2020: 182). El recordatorio de la victoria y la conquista habría tenido un mayor efecto si tales mensajes hubiesen sido recibidos y asumidos por las propias élites galaicas que acababan de ser conquistadas. Por último, en contra de una funcionalidad exclusivamente fiscal de la moneda en Gallaecia, no se entendería la política de centralización de las acuñaciones monetarias en tiempos de Chindasvinto (642-653). Si este monarca pudo centralizar las cecas en las ciudades galaicas, concretamente en Braga, Lugo y Tuy, es porque la actividad fiscal no requería necesariamente de un número ingente de cecas para funcionar. Si no lo era en aquellos momentos, tampoco en los de Recaredo. Por consiguiente, la proliferación de cecas en este territorio debía hundir sus causas en otro tipo de explicaciones, como las aquí defendidas. Asimismo, la retirada sistemática de numerario antiguo a lo largo de todo el período visigodo y la sustitución regular de este por uno nuevo podría entenderse, aparte de por un argumento fiscal (Retamero, 2011: 202), por la necesidad de la autoridad regia vigente en cada momento de reclamarse y afirmarse como autoridad soberana y, por tanto, como último responsable de la entrega de esa moneda.

Como hemos propuesto más arriba, insistimos en que nuestra argumentación no invalida una posible funcionalidad fiscal para la moneda, pero consideramos que esta habría tenido lugar en una fase posterior. De este modo, la entrega de "regalos" en forma de monedas habría adquirido un mayor protagonismo en los momentos iniciales y al comienzo de los reinados, como mecanismo primero y preferente de integración de las élites galaicas en las redes de fidelidad regias, siendo su función fiscal aquella que simbolizaría la sumisión de estas gentes en el largo recorrido. Esto es, la fiscalidad habría supuesto el paso posterior al establecimiento de unas relaciones de poder y dominación de la monarquía sobre las élites. Obviamente la tributación subyace un reconocimiento de la soberanía regia, pero no sería el instrumento a través del cual el rey lo conseguía, sino la consecuencia de un diálogo

49. Se observa una circulación del numerario de este monarca en torno a Toledo, pero también en la Septimania, el noreste de la Tarraconense y la región galaica. Barral i Altet, 1976: 150; Retamero, 2011: 218.

50. Más difícil resulta relacionar tales acuñaciones con la presencia del rey visigodo en estos enclaves, a pesar de lo propuesto recientemente por Andrew Kurt (2020: 152, 214-215). y de una negociación previas que concluyeron con la sumisión de las élites al poder regio. Más difícil resulta saber si esta tributación adquirió un carácter continuo en el tiempo y en el espacio galaico o, en cambio, esta se desarrolló únicamente de forma puntual con el fin exclusivo de remarcar simbólica y puntualmente a los potentes locales su integración en la esfera política toledana, opción esta última por la que nos inclinamos (Martín Viso, 2008b: 257).

Junto a los "regalos", debemos suponer que hubo otras vías de integración de las élites suevo-galaicas, como pudo ser la atribución de funciones de gobierno a través de cargos delegados ${ }^{51}$. Sin embargo, no contamos con pruebas que avalen esta hipótesis. Únicamente podemos especular al respecto. Lo mismo ocurre si intentamos distinguir distintos grados de deferencia por parte del poder visigodo hacia las élites suevogalaicas y que solo podemos suponer. Es de prever que los reyes visigodos habrían tratado de distinta forma a estas en función de la posición que habían ocupabado en la jerarquía interna del desaparecido reino o, en su defecto, de aquella que el nuevo régimen deseaba que ocupasen $^{52}$. Las élites locales, por ejemplo, habrían tenido menores oportunidades de acceder al monarca, frente a otras cuyo espectro de actuación e influencia era mayor.

La ocupación militar que se inició con Leovigildo habría tenido continuidad ${ }^{53}$, pero con el tiempo esta perdió la finalidad intimidatoria con la que se inició para adquirir un papel más defensivo. Es así como entendemos la presencia del dux Dogilán en la ciudad de Lugo (Vit. Fruct. 7; Díaz y Díaz, 1995: 242). A diferencia de los duces anteriormente citados, en este caso la misión de Dogilán, aun de corte eminentemente militar, habría tenido el fin de vigilar y proteger la región, en particular la costa, frente a posibles incursiones extranjeras (Novo Guisán, 1999-2000: 225-227). No es descartable que también hubiese tenido la misión de controlar a los astures y otros pueblos del norte (Díaz y Díaz, 1995: 242), puesto que es posible que muchos de estos grupos no hubieran llegado a ser sometidos en ningún momento de la historia visigoda (Poveda Arias,

51. En esta línea, Castellanos, 2008: 170. En un plano más general, véase también Bougard et al., 2013: 1083.

52. Aunque se trata únicamente de una hipótesis, es posible que los cinco aristócratas que aparecen en las actas del III Concilio de Toledo abjurando del arrianismo, y a los cuales se distingue del resto de seniores Gothorum, fuesen personajes de origen suevo. Conc. III Tol. (a. 589), Gothorum professio fidei, 586-596. En caso de aceptar este supuesto, debemos suponer que se trataban de potentes galaicos lo suficientemente destacados como para darles tal protagonismo en la reunión.

53. Como evidencia indirecta de esta ocupación militar podríamos entender el hecho de que el rebelde Segga, quien se conjuró en Mérida contra el obispo católico Masona y el rey Recaredo, acabase siendo condenado al exilio en la Gallaecia, donde habría estado presumiblemente muy vigilado. Ioh. Bicl., Chron. 87. 
2017). Esta última es la función que también podemos atribuirle al padre de Fructuoso de Braga, quien en un momento dado del segundo tercio del siglo VII nos encontramos desempeñando el cargo de $d u x$ en la región del Bierzo y liderando el exercitus Hispaniae. Más difícil resulta vislumbrar si su misión tuvo un carácter permanente o únicamente puntual, pero sí sabemos que en el transcurso de esta se le delegaron funciones fiscales (Vit. Fruct. 2, 1-5; Barbero y Vigil, 2012 [1970]: 81-87).

\section{LA INTEGRACIÓN DEL ESPACIO GALAICO EN EL REINO VISIGODO II: LA VERTIENTE ECLESIÁSTICA}

Mucha menos atención se ha prestado desde la historiografía a los mecanismos empleados por el poder visigodo para integrar las estructuras eclesiásticas del espacio suevo. No se trata de una cuestión baladí, puesto que la Iglesia era el poder que mayor penetración territorial tenía, tal y como refleja el Parrochiale Sueuum. Es de prever que el propio poder suevo se aprovechó de ello cuando se dispuso a articular territorial y administrativamente el reino (Díaz, 1998; 2015) pero es igualmente asumible atribuir una actitud similar al poder visigodo (Castellanos, 2011: 207-208). Aunque en este caso tampoco disponemos de mucha información, sí contamos con algunas pistas aisladas que nos pueden ayudar a aproximarnos al trato dispensado por Leovigildo y Recaredo a la Iglesia sueva y a sus principales representantes.

En las actas del III Concilio de Toledo del 589, en el que se oficializó la conversión de todo el reino visigodo al catolicismo, suscriben la abjuración del arrianismo una serie de obispos procedentes del antiguo reino suevo, concretamente los titulares de Lugo, Tuy, Oporto y Viseu (Conc. III Tol. [a. 589], Gothorum professio fidei). Descartamos que estos obispos hubiesen sido nombrados en la fase sueva, puesto que este reino oficializó su conversión al catolicismo años atrás (Thompson, 1980; Dumézil, 2005: 270-274; García Moreno, 2006). También excluimos la posibilidad de que los hubiese nombrado Recaredo, puesto que este monarca impulsó la adopción general por parte del reino -incluidos los antiguos integrantes del reino suevo- del credo niceno desde el primer año de su reinado (Ioh. Bicl., Chron. 84). Debemos suponer, por tanto, que se trataban de obispos designados por el propio Leovigildo, que creó ex novo cátedras episcopales arrianas en el contexto abierto por la conquista del reino suevo (Beltrán Torreira, 1989; Díaz y Díaz, 1995:

54. Resultan bastante elocuentes las palabras de Isabel Velázquez (2000: 588) al respecto de esta cuestión: "hasta qué punto no es la Iglesia la verdadera responsable de la organización no sólo eclesiástica, sino social, del territorio controlado por la monarquía sueva".
238-239; Freán Campo, 2019: 348); un movimiento que estimamos que estaba destinado en última instancia a lograr un control efectivo de los territorios recientemente adquiridos (Thompson, 1980: 25). La promoción de obispos arrianos en estas ciudades no implicó, sin embargo, la desaparición de los obispados católicos, puesto que al citado concilio asistieron también los prelados católicos de estas ciudades. De hecho, es posible que en algún caso el nuevo obispo arriano hubiese ocupado previamente la cátedra episcopal católica y que para esta última se hubiese nombrado un nuevo titular. Esta es la situación que intuimos, por ejemplo, para el caso de Viseu y su obispo arriano Sunila ${ }^{55}$. Sin embargo, en la mayoría de casos debemos suponer que el obispo arriano había sido nombrado ex novo, puesto que algunos de los obispos católicos, como Nitigisio de Lugo, lo eran desde tiempos relativamente pretéritos (Thompson, 2011 [1969]: 109).

Observamos por tanto cómo, en contraste con su actitud en el plano secular, Leovigildo desplegó en la esfera eclesiástica una política mucho más intervencionista. Debemos preguntarnos a continuación por las razones y los objetivos que motivaron esta estrategia. En primer lugar, descartamos que Leovigildo hubiese buscado imponer el arrianismo en el territorio galaico como nueva religión oficial. Si así hubiera sido, no se entiende que conservase las cátedras católicas, permitiendo incluso su sucesión natural ${ }^{56}$, ni tampoco el alcance limitado de su política, la cual aplicó únicamente a cuatro sedes episcopales. Como en el resto del territorio del regnum, se siguió el esquema de mantener una dualidad de cátedras episcopales, una católica y otra arriana ${ }^{57}$. Para responder a esta cuestión, resulta bastante elocuente la elección de las sedes en cuestión. En particular, tres de ellas, Lugo, Tuy y Oporto, coinciden con aquellas cecas donde se emitieron monedas conmemorativas de la victoria visigoda

55. Ello explicaría porqué el obispo Sunila de Viseu subscribe las actas del III Concilio de Toledo en una posición tan elevada, lo que daría a entender que todos los demás obispos, los veintiocho que subscriben después que él, fueron ordenados después que él. Esta idea ya se ha desarrollado para el estudio de los concilios galos entre los siglos IV y V (Mathisen, 1990). En este caso, si damos como válidas las hipótesis de Luis A. García Moreno (1974b: 186, n. 517. 1,), la cátedra católica habría sido ocupada ahora por un tal Juan. Abogando también por esta posibilidad, Mansilla Reoyo, 1995: 210, aunque en otro punto de su obra entra en contradicción y lo considera titular de Valeria (Mansilla Reoyo, 1995: 290); Dumézil, 2005: 645.

56. En concreto, los obispos católicos de Iría, Oporto, Lamego y Viseu habrían sido nombrados probablemente en los años de gobierno de Leovigildo sobre la región. En una línea similar, Beltrán Torreira, 1989: 73-74.

57. Haciendo un balance similar, Thomspon, 2011 [1969]: 110: "la consecuencia fue que cuando Leovigildo conquistó Galicia no acabó con la organización de la Iglesia católica en la provincia: simplemente instaló al lado de ella una organización arriana". 
y las cuales asociamos más arriba a aquellos centros de poder más resistentes al poder visigodo. Es posible, por tanto, poner en relación la promoción de obispos arrianos en estas sedes con esas mismas resistencias. Federico Beltrán asoció, en una lectura que no tiene que entrar en contradicción a la nuestra, la existencia de estos obispados arrianos con la presencia de guarniciones militares visigodas, pero únicamente intuyó en la iniciativa de Leovigildo unas "consideraciones estratégicas" (Beltrán Torreira, 1989) ${ }^{58}$. Por nuestra parte, planteamos la posibilidad de que la creación de estas cátedras episcopales arrianas, con sus consiguientes estructuras eclesiásticas, fue un movimiento dirigido a perjudicar y debilitar a los obispos católicos de estas ciudades. En concreto, al promocionar a un obispo arriano en una comunidad con un homólogo católico, el visigodo habría pretendido introducir elementos de competencia interna en las comunidades cristianas suevas. A fin de cuentas, la mera convivencia de dos obispos en una misma sede habría generado tensiones entre ambos, siendo el caso de Mérida, con la conocida lucha entre el católico Masona y su homólogo arriano Sunna, bastante elocuente al respecto. En caso de estar en lo cierto, el movimiento de Leovigildo estaría denotando la incapacidad por parte del monarca visigodo de atraerse el apoyo de los obispos católicos de estas ciudades ${ }^{59}$.

Debemos sin embargo excluir de este modelo explicativo el caso de Viseu, curiosamente la única de las sedes arrianas del antiguo reino suevo donde no contamos con acuñaciones conmemorativas de las victorias visigodas. En este caso es posible que hubiese sido el propio Sunila quien hubiese optado por convertirse al arrianismo como un guiño al propio Leovigildo, ante unas eventuales aspiraciones de gozar de una mayor cercanía con el monarca ${ }^{60}$. Sunila habría seguido así la estela de Vicente de Zaragoza, quien también se convirtió al arrianismo y pasó a ocupar una cátedra arriana de nueva creación en su sede de origen (Isid. Hisp., Hist. 50). Sin embargo, se tratan de casos bastante excepcionales.

Llama la atención que no contemos con un obispado arriano en la sede metropolitana de Braga, lo que sorprende aún más atendiendo a su papel como capital

58. Una línea similar defendió en su momento: Orlandis, 1976: 51-53.

59. Cabe la posibilidad, como se ha planteado, de que este despliegue de obispados arrianos en el antiguo reino suevo se hubiese producido después del fallido intento de restauración del reino por Malarico (García Moreno, 2008: 171).

60. Si el orden de las suscripciones episcopales en las actas conciliares supone un reflejo de la antigüedad del cargo del obispo en cuestión, Sunila figura como el primer obispo galaico que obtuvo su cátedra arriana, lo que concuerda con que fuera él mismo quien tomó la iniciativa (Conc. III Tol. [a. 589], Gothorum profession fidei; Dumézil, 2005: 648-650). del reino suevo ${ }^{61}$ ¿QQué factores influyeron en este trato diferencial hacia la sede metropolitana? Caben dos posibilidades interpretativas, difíciles de confirmar. Por un lado, podríamos entender este movimiento como un intento consciente de desprestigiarla y degradarla como centro de poder, en este caso en el campo eclesiástico (Díaz, 2000: 419-420); una actitud que, por ejemplo, puede explicar también por qué Leovigildo no nombró obispos arrianos en Sevilla y Tarragona. Sin embargo, también podríamos entenderlo como una evidencia indirecta del apoyo prestado por el metropolitano de Braga, Pantardo, al poder visigodo desde el momento de la conquista del reino suevo. De hecho, las evidencias apuntan más hacia esta última dirección. Pocos años antes de la conquista del reino suevo por los visigodos, se llevó a cabo una reorganización de las estructuras territoriales de la Iglesia sueva. En concreto, se asume que el reino se dividió en dos distritos eclesiásticos, uno encabezado por Braga y otro por la sede de Lugo, cuyo obispo habría recibido a partir de ese momento el trato de metropolitano (Thompson, 1980: 90; Díaz y Díaz, 1995: 239-240; Barbero, 1998: 182183; Escalona Monge, 206: 192; Núñez García, 2013 : 26; Barroso Cabrera et al., 2015: 74; Ubric Rabaneda, 2015: 224; Fernández Calo, 2016). Así se deduce del apartado suscriptorio de las actas del II Concilio de Braga del 572, donde se denomina a la sede lucense como metropolitana y se integra a las sedes de Iría, Auria, Tui, Astorga y Britonia en el Lucensi synodo (Conc. II Brac. [572], Subscr.). También Martín de Braga intitula en sus Capitula ex Orientalium patrum synodis a Nitigisio de Lugo como obispo "vel universo concilio Lucensis ecclesiae" (Mart. Brac., Cap. Ex Orient. Patr. Syn. Praef. $)^{62}$. Algunos han atribuido esta división territorial a la voluntad del monarca suevo Teodomiro (Barbero, 1992: 197; Fernández Calo, 2016: 145-149), pero se trata de un supuesto difícil de confirmar. Más allá de si la sede de Lugo recibió una confirmación oficial de su rango metropolitano, las evidencias apuntan a que al menos su obispo disfrutó de forma factual de esta posición, poniéndolo en cierta manera al mismo nivel que el metropolitano de Braga (Novo Guisán, 1997-1998: 185). Sin embargo, después de la conquista visigoda del reino suevo, desaparecerá

61. Algunos no descartan que se hubiese nombrado un obispo arriano en esta ciudad (Dumézil, 2005: 274, 652).

62. Más cuestionable es la validez del preámbulo del Parrochiale Sueuum, donde se dice que la nueva organización eclesiástica se concretó y acordó en un supuesto concilio celebrado en Lugo. Sin embargo, es posible que estemos ante una interpolación posterior del Parrochiale. David, 1947; Díaz, 2000: 413; Núñez García, 2013: 413. Otorgan sin embargo validez a este preámbulo: Thompson, 1980: 88-90; Novo Guisán, 1997-1998: 184; Barbero, 1992: 184-187; García Moreno, 2006; Fernández Calo, 2016. 
todo trato diferencial hacia los obispos de $\operatorname{Lugo}^{63}$. Observamos, por tanto, que los visigodos, fuera por iniciativa de Leovigildo o de Recaredo, no aceptaron el orden de cosas vigente $y$, en un movimiento inédito, revirtieron la reforma eclesiástica sueva privándole a la sede de Lugo, y por ende a su obispo, de cualquier tipo de jurisdicción superior sobre las diócesis de su entorno. Es quizás por ello, como una forma de mostrar su descontento por su posición perdida, por lo que el titular católico de Lugo no asistió al III Concilio de Toledo (Beltrán Torreira, 1989: 76) ${ }^{64}$. Se ha planteado que este movimiento se debió a que, con la conquista visigoda, la sede bracarense perdió la jurisdicción sobre buena parte de las diócesis más meridionales que fueron integradas en la provincia eclesiástica lusitana, siendo las diócesis del distrito lucense incorporadas en la provincia bracarense (Barroso Cabrera et al., 2015: 76). Sin embargo, lo más probable es que esta última reorganización no se hubiese dado hasta los tiempos de Recesvinto (véase infra). De este modo, Braga recuperó la jurisdicción sobre el conjunto de las diócesis del desaparecido reino suevo, lo que no concuerda con un posible intento de degradación de su posición, al menos en la esfera eclesiástica. Al contrario, el trato dispensado por los visigodos al obispo de Lugo, unido a la ausencia de obispos arrianos en la antigua capital sueva, apuntan a un alineamiento temprano de Pantardo de Braga al régimen visigodo.

Braga mantuvo a lo largo del período visigodo su primacía eclesiástica en la Gallaecia, no así en el plano político y administrativo, donde la antigua capital sueva perdió paulatinamente protagonismo en favor de Tuy y Lugo. Ya hemos hecho alusión a la presencia del $d u x$ Dogilán en esta última. En el caso de Tuy, de la cual destaca su proximidad geográfica a Braga, sabemos que aquí residió Witiza poco antes de su ascenso al trono ${ }^{65}$. Asimismo, sabemos que, desde el mismo momento de la conquista, Tuy empezó a destacar por encima de cualquier otra ciudad de la región como centro emisor de moneda (Pliego, 2009: 119) ${ }^{66}$. En definitiva, da la sensación de que el poder visigodo desplegó una política de pesos y contrapesos en las ciudades más importantes del antiguo reino suevo, favoreciendo a unas en un plano, al mismo tiempo que las debilitaba en otro.

63. En las actas conciliares del período visigodo los titulares de Lugo figuran al mismo nivel que el resto de los obispos sufragáneos.

64. De todas formas, tampoco debemos descartar como posible factor de su ausencia su avanzada edad (Dumézil, 2005: $653)$.

65. Chron. Adeph. III - Rot/Seb 4. Sobre las posibles circunstancias que pudieron motivar este movimiento, Díaz, 2006: 213-214, aunque descartamos que este hubiese obedecido a una posible amenaza de segregación del espacio galaico del reino visigodo.

66. Más difícil nos resulta vislumbrar si esta relevancia política y administrativa tenía una relación militar, como en el caso de Lugo.
Ciertamente, hubo un mayor intervencionismo en la esfera eclesiástica, pero sin plantear cambios traumáticos. Por ejemplo, como hemos adelantado, todavía en estos momentos no se entregó a Mérida la jurisdicción sobre componentes territoriales que originalmente formaron parte de la provincia eclesiástica lusitana. Dicha restructuración territorial no se produjo hasta el reinado de Recesvinto (653-672) ${ }^{67}$, disfrutando por tanto Braga de una primacía eclesiástica sobre el cuadrante noroccidental de la península ibérica durante siete decenios. La nueva organización provincial se formalizó en el Concilio de Mérida del 666, pero que debió venir precedido por un proceso previo de negociación entre los obispos antes integrados en la provincia eclesiástica galaica y la sede Mérida con el cual el obispo metropolitano lusitano se aseguró la lealtad de sus nuevos sufragáneos (Conc. Emeret. [a. 666], c. 8; Poveda Arias, 2019: 19-20). No debemos, sin embargo, pensar que esta reorganización pretendió volver a un orden de cosas previo que no se daba en todo caso desde el siglo V (Cf. Díaz, 1992: 311-321; 1995: 51-72), sino únicamente adaptar el esquema administrativo a las necesidades del momento ${ }^{68}$. De hecho, la provincia eclesiástica de Gallaecia no recuperó en ningún momento sus límites originales, al menos en lo que a sus demarcaciones orientales se refiere ${ }^{69}$.

\section{CONCLUSIONES}

A lo largo de las páginas anteriores hemos intentado abrir nuevas ventanas interpretativas en torno a las circunstancias y, en particular, a las motivaciones que llevaron a los visigodos a conquistar el reino suevo. Concretamente, hemos abierto la posibilidad de que la conquista en cuestión distó de formar parte de un proyecto ambicioso de unificación política y territorial de la península ibérica bajo soberanía visigoda. De este modo, y huyendo de maximalismos, hemos propuesto que en realidad la absorción definitiva de la Gallaecia en el regnum Gothorum fue debida a factores coyunturales, en particular como consecuencia de la usurpación de Audeca del trono suevo y la posibilidad que esta abría de una confrontación abierta con los visigodos.

De todas formas, más allá de las circunstancias concretas, la conquista del reino suevo abrió la puerta a un largo proceso de integración del espacio y la sociedad galaicas dentro de las estructuras políticas visigodas, y que exigía intervenir en un plano secular, pero también eclesiástico. En lo referido al primero, hemos abogado por el protagonismo de la negociación con las élites

67. Beltrán Torreira, 1989: 76; Novo Guisán, 1997-1998: 186; Díaz, 2004: 374; Ubric Rabaneda, 2015: 224.

68. Remarcan este esquema más transformativo de las provincias eclesiásticas en época visigoda: Martin, 2003: 72; Pachá, 2019.

69. Sobre los límites antiguos de la Gallaecia, Torres, 1949; Escalona Monge, 2006: 178. 
locales, sin que ello supusiese renunciar, al menos en una primera fase, a la vía intimidatoria que representaban los duces visigodos desplegados en la región. Ante la falta de fuentes escritas que nos ofrezcan pistas sobre las formas que tomaron estas negociaciones, el registro numismático se ha tornado un testimonio fundamental. Sobre este, hemos ahondado en el papel de las monedas como "regalos" entregados por parte de los visigodos a las élites suevo-galaicas con el fin de fijar la lealtad de estas al nuevo poder vigente. Estos se habrían complementado con otras estrategias igualmente conciliadoras con los conquistados, siendo una de ellas la continuidad de las estructuras administrativas precedentes, entre otras.

Más intervencionista, sin embargo, fue el poder visigodo en el plano eclesiástico. En él observamos, por un lado, la promoción de obispados arrianos en tiempos de Leovigildo y, por otro, ya con Recaredo, una manipulación de la geografía eclesiástica construida en la etapa final del reino suevo, que dio pie a la pérdida del rango metropolitano por parte del obispo de Lugo, mientras la sede de Braga recibía un trato mucho más amable. No descartamos que en estos movimientos hubiesen influido, entre otros factores, las distintas afinidades políticas de los obispos implicados. En suma, es indudable el éxito que Leovigilido y Recaredo tuvieron a la hora de integrar dentro del reino visigodo el desaparecido reino suevo, y en particular a sus élites laicas y eclesiásticas, sin que ello hubiese supuesto un menoscabo a las propias particularidades e idiosincrasia de la región, las cuales se mantuvieron a lo largo de todo el período.

\section{FUENTES PRIMARIAS}

Concilios visigóticos e hispano-romanos. (Ed. J. Vives, 1963). Barcelona - Madrid: CSIC.

Chron. Adeph. III = Chronica Adephonsi III. (Ed. J. Gil, 2018). Chronica hispana saeculi VIII et IX. Turnhout: Brepols.

Greg. Tur., $D L H=$ Gregorius Turonensis, Decem Libri Historiae. (Ed. B. Krusch y W. Levison, 1951). Gregorii Episcopi Turonensis Historiarum Libri X(MGH, SRM T I, P I). Hannover: Impensis Bibliopolii Hahniani.

Ioh. Bicl., Chron. = Iohannes Biclarensis, Chronicon. (Ed. C. Cardelle de Hartmann, 2001). Victoris Tvnnvnensis Chronicon cum reliquiis ex Consvlaribvs Caesaravgvstanis et Iohannis biclarensis Chronicon (CC, SL 173A). Turnhout: Brepols.

Isid. Hisp., Chron. = Isidorus Hispalensis, Chronica. (Ed. J. C. Martín Iglesias, 2003). Isidori Hispalensis Chronica (CC, SL 112). Turnhout: Brepols.

Isid. Hisp., Hist. = Isidorus Hispalensis, Historiae. (Ed. C. Rodríguez Alonso, 1975). Las Historias de los godos, vándalos y suevos de Isidoro de Sevilla. León: Archivo Histórico Diocesano.
La colección canónica hispana, V. Concilios hispanos: segunda parte. (Eds. G. Martínez Díez y F. Rodríguez Barbero, 1992). Madrid: CSIC.

Mart. Brac., Cap. Ex Orient. Patr. Syn. = Martinus Bracarensis, Capitula ex Orientalium patrum synodis. (Ed. C. W. Barlow, 1950). Martini episcopi Bracarensis opera omnia. New Haven - London - Oxford: Yale University Press - G. Cumberlege - Oxford University Press.

Vit. Fruct. $=$ Vita Fructuosi. (Ed. M. C. Díaz y Díaz, 1974). Braga: R. P. Baudouin De Gaiffier, S. I., Bolandista.

VSPE = Vitas Sanctorum Patrum Emeretensium. (Ed. A. Maya, 1992) (CC, SL 116). Turnhout: Brepols.

\section{REFERENCIAS}

Arce, J. (2011). Esperando a los árabes. Los visigodos en Hispania (507-711). Madrid: Marcial Pons.

Barbero, A. (1992). Las divisiones eclesiásticas y las relaciones entre la Iglesia y el Estado en la España de los siglos VI y VII. En La sociedad visigoda y su entorno histórico (pp. 168-198). Madrid: Siglo XXI.

Barbero, A. y Vigil, M. (1978). La formación del feudalismo en la Península Ibérica. Barcelona: Crítica.

Barbero, A. y Vigil, M. (2012 [1970]). Algunos aspectos de la feudalización del reino visigodo en relación con su organización financiera y militar. En Visigodos, cántabros y vascones en los orígenes sociales de la Reconquista (pp. 73-95). Pamplona: Urgoiti.

Barceló, M. (1999). De fisco gotico, hispánico sive andalusico. Faventia, 21(1), 103-118.

Barral i Altet, X. (1976). La circulation des monnaies suèves et visigothiques. München: Artemis Verlag.

Barroso Cabrera, R., Morín de Pablos, J. y Sánchez Ramos, I. M. . . (2015). Gallaecia gothica: de la conspiración del Dux Argimundus (589-590 d. C.) a la integración en el Reino visigodo de Toledo. Madrid: Audema.

Beltrán Torreira, F. M. (1989). La conversión de los suevos y el III Concilio de Toledo. Mayurqa: revista del Departament de Ciències Històriques i Teoria de les Arts, 22(1), 69-84.

Bougard, F., Bührer Thierry, G. y Le Jan, R. (2013). Les élites du haut Moyen Âge. Identités, stratégies, mobilité. Annales. Histoire, Sciences Sociales, 68(4), 1079-1112. DOI: https:// doi.org/10.1017/s0395264900015110

Bronisch, A. P. (2006). El concepto de España en la historiografía visigoda y cristiana. Norba. Revista de Historia, 19, 9-42.

Carneiro, R. L. (1978). Political Expansion as an Expression of the Principle of Competitive Exclusion. En R. Cohen y E. R. Service (Eds.). Origins of the State. The Anthropology of Political Evolution (pp. 205-223). Philadelphia: Institute for the Study of Human Issues.

Castellanos, S. (2008). La construcción del poder político visigodo y los horizontes locales: canales de participación 
y hostilidad. En S. Castellanos e I. Martín Viso (Eds.). De Roma a los bárbaros. Poder central y horizontes locales en la cuenca del Duero (pp. 145-170). León: Universidad de León.

Castellanos, S. (2011). Tributa and Historiae: Scale and Power at a Turning Point in Post-Roman Spain. En J. Escalona y A. Reynolds (Eds.). Scale and Scale Change in the Early Middle Ages. Exploring Landscape, Local Society, and the World Beyond (pp. 187-214). Turnhout: Brepols. DOI: https://doi.org/10.1484/m.tmc-eb.3.4773

Castellanos, S. y Martín Viso I. (2005). The Local Articulation of Central Power in the North of the Iberian Peninsula (500-1000). Early Medieval Europe, 13(1), 1-43. DOI: https://doi.org/10.1111/j.1468-0254.2005.00147.x

Carvajal Castro, Á. (2017). Bajo la máscara del regnum. La monarquía asturleonesa en León (854-1037). Madrid: CSIC.

Coupland, S. (1999). The Frankish Tribute Payments to the Vikings and their Consequences. Francia, 26(1), 57-75.

David, P. (1947). Études historiques sur la Galice et le Portugal du VI au XII siècle. Paris: Les Belles Lettres.

Deswarte, T. (2014). Une nation inachevée: le royaume de Tolède (VI ${ }^{\mathrm{e}}-\mathrm{VII}{ }^{\mathrm{e}}$ siècle). En Nation et nations au Moyen Âge (pp. 63-78). Paris: Publications de la Sorbonne. DOI: https:// doi.org/10.4000/books.psorbonne.21654

Díaz, P. C. (1992). Salamanca tardoantigua y visigoda. En Actas I Congreso Historia de Salamanca (pp. 311-321). Salamanca: Diputación Provincial de Salamanca - Universidad de Salamanca.

Díaz, P. C. (1995). Propiedad y poder: la Iglesia lusitana en el siglo VII. En Los últimos romanos en Lusitania (pp. 51-72). Mérida: Museo Nacional de Arte Romano.

Díaz, P. C. (1997). Gallaecia: de reino suevo a provincia visigoda. En G. Pereira-Meanut (Ed.). Galicia fai dous mil anos: o feito diferencial galego, I, Historia (pp. 253-278). Santiago de Compostela: Museo do Pobo Galego - A Editorial da Historia.

Díaz, P. C. (1998). El Parrochiale Suevum: organización eclesiástica, poder político y poblamiento en la Gallaecia tardoantigua. En J. Alvar (Ed.). Homenaje a José María Blázquez, vol. 6. Antigüedad: religiones y sociedad (pp. 35-48). Madrid: Ediciones Clásicas.

Díaz, P. C. (2000). El nuevo reino suevo de Hispania y su sede en Bracara. En G. Ripoll López y J. M. ${ }^{a}$ Gurt Esparraguera (Eds.). Sedes regiae (ann. 400-800) (pp. 403-423). Barcelona: Reial Acadèmia de Bones Lletres.

Díaz, P. C. (2004). Acuñación monetaria y organización administrativa en la Gallaecia tardoantigua. Zephyrus, 57, 367-375.

Díaz, P. C. (2006). Extremis mundo partibus. Gallaecia tardoantigua: periferia geográfica e integración política. En U. Espinosa y S. Castellanos (Eds.). Comunidades locales $y$ dinámicas de poder en el norte de la península ibérica durante la Antigüedad Tardía (pp. 201-206). Logroño: Universidad de La Rioja.
Díaz, P. C. (2008). El siglo VI en Galia e Hispania a través de las fuentes escritas. Zona Arqueológica, 11, 348-363.

Díaz, P. C. (2011). El reino suevo (411-585). Madrid: Akal.

Díaz, P. C. (2012). Confiscations in the Visigothic Reign of Toledo: A Political Instrument. En P. Porena e Y. Rivière (Eds.). Expropriations et confiscations dans les royaumes barbares. Une approche régionale (pp. 93-112). Roma: École Française de Rome.

Díaz, P. C. (2015). La organización del espacio y el control del territorio en la Gallaecia germánica. En G. Pereira-Menaut y E. Portela Silva (Eds.). El territorio en la historia de Galicia. Organización y control. Siglos I-XXI (pp. 37-95). Santiago de Compostela: Universidade de Santiago de Compostela.

Díaz, P. C. (2019). El esquema provincial en el contexto administrativo de la monarquía visigoda de Toledo. Mélanges de la Casa de Velázquez, 49(2), 125-135. DOI: https:// doi.org/10.4000/mcv.11009

Díaz, P. C. y Valverde Castro, M. ${ }^{a}$ R. (2000). The Theoretical Strength and Practical Weakness of the Visigothic Monarchy of Toledo. En F. Theuws y J. L. Nelson (Eds.). Rituals of Power. From Late Antiquity to the Early Middle Ages (pp. 59-93). Leiden: Brill. DOI: https://doi. org/10.1163/9789004477551 006

Díaz y Díaz, M. C. (1995). Notas sobre el Distrito de Lugo en la época Sueva. Helmántica: revista de filología clásica $y$ hebrea, 46(139-141), 227-242.

Doménech Belda, C. (2014). Moneda y espacios de poder en el reino visigodo. Los tremises de El Tolmo de Minateda (Hellín, Albacete). Arqueología y Territorio Medieval, 21, 9-37. DOI: https://doi.org/10.17561/aytm.v21i0.2219

Dumézil, B. (2005). Les racines chrétiennes de l'Europe. Conversion et liberté dans les royaumes barbares. $V^{t}$-VIII siècle. Paris: Fayard.

Dumézil, B. (2015). La chancellerie mérovingienne au VI ${ }^{\mathrm{e}}$ siècle. En Le corti nell'alto Medioevo (pp. 473-500). Spoleto: CISAM.

Escalona Monge, J. (2006). Patrones de fragmentación territorial: el fin del mundo romano en La Meseta del Duero. En U. Espinosa y S. Castellanos (Eds.). Comunidades locales y dinámicas de poder en el norte de la península ibérica durante la Antigüedad Tardía (pp. 165-200). Logroño: Universidad de La Rioja.

Fernández, D. (2017). Aristocrats and Statehood in Western Iberia, 300-600 C.E. Philadephia: University of Pennsylvania Press. DOI: https://doi.org/10.9783/9780812294354

Fernández Calo, M. (2016). Os synodi suevo-católicos: implicacións político-administrativas dunha bipartición metropolitana. Cuadernos de Estudios Gallegos, 63(129), 126-162. DOI: https://doi.org/10.3989/ceg.2016.129.04

Freán Campo, A. (2019). La arrianización del reino suevo: alcance y consecuencias. En J. López Vilar (Ed.). Tarraco Biennal. Actes 4 congrés Internacional d'Arqueologia $i$ Món Antic. VII Reunió d'Arqueologia cristiana hispánica. El cristianisme en l'Antiguitat Tardana. Noves Perspectives 
(345-350). Tarragona: Universitat Rovira i Virgili - Institut d'Estudis Catalans.

Frighetto, R. (2015). El exilio, el destierro y sus concepciones políticas en la Hispania visigoda: los ejemplos de Juan de Bíclaro e Isidoro de Sevilla (siglos VI-VII). En M. Vallejo Girvés, J. A. Bueno Delgado y C. Sánchez-Moreno Ellart (Eds.). Movilidad forzada entre la Antigüedad Clásica y Tardía (pp. 111-134). Alcalá de Henares: Universidad de Alcalá.

García Moreno, L. A. (1974a). Estudios sobre la organización administrativa del reino visigodo de Toledo. Anuario de Historia del Derecho Español, 44, 5-155.

García Moreno, L. A. (1974b). Prosopografía del reino visigodo de Toledo. Salamanca: Universidad de Salamanca.

García Moreno, L. A. (1982). Cecas visigodas y sistema económico. En P. de Palol (Ed.). II reunió d'arqueologia paleocristiana hispánica (pp. 333-345). Barcelona: Institut d'Arqueologia i Prehistòria.

García Moreno, L. A. (2006). La Iglesia y el cristianismo en la Galecia de época sueva. Antigüedad y Cristianismo, $23,39-56$.

García Moreno, L. A. (2008). Leovigildo. Unidad y diversidad de un reinado. Madrid: Real Academia de la Historia.

Gibert, R. (1956): El reino visigodo y el particularismo español. En I goti in Occidente (pp. 537-584). Spoleto: CISAM.

Godelier, M. (1989 [1984]). Lo ideal y lo material. Madrid: Taurus.

Grierson, P. (1959). Commerce in the Dark Ages: A critique of the Evidence. Transactions of the Royal Historical Society, Fifth Series, 9, 123-140. DOI: https://doi. org/10.2307/3678808

Grierson, P. (1962). A Tremissis of the Suevic King Audeca (584-5). Estudos di Castelo Branco, 2(6), 27-32.

Halsall, G. (1998). Social Identities and Social Relationships in Early Merovingian Gaul. En I. Wood (Ed.). Franks and Alamanni in the Merovingian Period: An Ethnographic Perspective (pp. 141-165). Woodbridge: Boydell Press.

Halsall, G. (2018): Predatory Warfare - the Moral and the Physical. En R. Keller y L. Sarti (Eds.). Pillages, tributs, captifs : Prédation et sociétés de l'Antiquité tardive au haut Moyen Âge (pp. 53-68). Paris: Éditions de la Sorbonne. DOI: https://doi.org/10.4000/books.psorbonne.39940

Hardt, M. (1998). Royal Treasures and Representation in the Early Middle Ages. En W. Pohl y H. Reimitz (Eds.). Strategies of Distinction. The Construction of Ethnic Communities, 300-800 (pp. 255-280). Leiden: Brill.

Innes, M. (2000). State and Society in the Early Middle Ages: The Middle Rhine Valley, 400-1000. Cambridge: Cambridge University Press. DOI: https://doi.org/10.1017/ cbo9780511496349

Kaiser, R. (2003). L'entourage des rois du regnum Burgundiae aux époques burgonde et mérovingienne. En A. Marchandisse y J. L. Kupper (Eds.). A l'ombre du pouvoir. Les entourages princiers au Moyen Age (pp. 77-95). Genève: Librairie Droz. DOI: https://doi.org/10.4000/books.pulg.5640

Keller, R. (2013). Les profits de la guerre : Prédation et Pouvoir dans le monde franc ( $V I^{e}-X^{e}$ siècle). (Tesis doctoral). Université de Paris Est. Paris. DOI: https://doi.org/10.4000/ ifha. 8057

Kulikowski, M. (2012). The Western Kingdoms. En S. F. Johnson (Ed.). The Oxford Handbook of Late Antiquity (pp. 31-59). Oxford: Oxford University Press. DOI: https://doi. org/10.1093/oxfordhb/9780195336931.013.0001

Kurt, A. (2009). The Places and Purposes of Minting in the Earliest Medieval Kingdoms. En B. A. Catlos (Ed.). Worlds of History and Economics. Essays in Honour of Andrew M. Watson (pp. 33-54). Valencia: Universitat de València.

Kurt, A. (2020). Minting, State, and Economy in the Visigothic Kingdom: From Settlement in Aquitaine through the First Decade of the Muslim Conquest of Spain. Amsterdam: Amsterdam University Press. DOI: https://doi.org/10.2307/j. ctvzgb77v

Le Jan, R. (2010). Prendre, accumuler, détruire les richesses dans les sociétés du Haut Moyen Âge. En R. Le Jan, L. Feller y J.-P. Devroey (Eds.). Les élites et la richesse au haut Moyen Age (pp. 365-382). Turnhout: Brepols. DOI: https:// doi.org/10.1484/m.hama-eb.3.4675

Magnou-Nortier, E. (1996). Du royaume des civitates au royaume des honores. Episcopatus, comitatus, abbatia dans le royaume franc ( $\mathrm{VI}^{\mathrm{e}}-\mathrm{IX}^{\mathrm{e}}$ siècle). En C. Lepelley (Ed.). $L a$ fin de la cité antique et le début de la cité médiévale: de la fin du III siècle à l'avènement de Charlemagne (pp. 311-344). Bari: Edipuglia.

Mansilla Reoyo, D. (1994). Geografía eclesiástica de España. Estudio histórico-geográfico de las diócesis, I. Roma: Iglesia Nacional Española.

Martin, C. (2003). La géographie du pouvoir dans l'Espagne visigothique. Villeneuve d'Ascq: Presses Universitaires du Septentrion. DOI: https://doi.org/10.4000/books. septentrion.53176

Martín Viso, I. (2008a). Tremisses y potentes en el nordeste de Lusitania (siglos VI-VII). Mélanges de la Casa de Velázquez, 38, 175-200. DOI: https://doi.org/10.4000/mcv.1017

Martín Viso, I. (2008b). La ordenación del territorio rural y la tributación en el suroeste de la Meseta del Duero (siglos VI-VII). En S. Castellanos e I. Martín Viso (Eds.). De Roma a los bárbaros. Poder central y horizontes locales en la cuenca del Duero (pp. 227-261). León: Universidad de León.

Martín Viso, I. (2011). Circuits of Power in a Fragmented Space: Gold Coinage in the Meseta del Duero (Sixth-Seventh Centuries). En J. Escalona y A. Reynolds (Eds.). Scale and Scale Change in the Early Middle Ages: Exploring Landscape, Local Society, and the World Beyond. Turnhout: Brepols: 215-252. DOI: https://doi.org/10.1484/m. tmc-eb.3.4774

Martín Viso, I. (2013). Prácticas locales de la fiscalidad en el reino visigodo de Toledo. En X. Ballestín y E. 
Pastor (Eds.). Lo que vino de Oriente. Horizontes, praxis $y$ dimensión material de los sistemas de dominación fiscal en Al-Ándalus (ss. VII-IX) (pp. 72-85). BAR International Series, 2525. Oxford: Archaeopress. DOI: https://doi. org/10.30861/9781407311432

Martín Viso, I. (2015). La moneda y la articulación política del regnum Gothorum. En J. A. Quirós Castillo y S. Castellanos (Eds.). Identidad y etnicidad en Hispania. Propuestas teóricas y cultura material en los siglos V-VIII (pp. 101-124). Bilbao: Servicio Editorial de la Universidad del País Vasco.

Mathisen, R. W. (1990). Episcopal Hierarchy and Tenure in Office in Late Roman Gaul: A Method for Establishing Dates of Ordination. Francia, 17(1), 125-140.

Metcalf, D. M. (1999). Visigothic Monetary History. The Facts, What Facts? En A. Ferreiro (Ed.). The Visigoths. Studies in Culture and Society (pp. 201-217). Leiden: Brill. DOI: https://doi.org/10.1163/9789004474581_010

Miles, G. C. (1952). The Coinage of the Visigoths of Spain. Leovigild to Achila. New York: The American Numismatic Society.

Naismith, R. (2014a). The Social Significance of Monetization in the Early Middle Ages. Past \& Present, 223, 3-39. DOI: https://doi.org/10.1093/pastj/gtu004

Naismith, R. (2014b). Gold Coinage and its Use in the PostRoman West. Speculum, 89(2), 273-306. DOI: https://doi. org/10.1017/s0038713413004533

Novo Guisán, J. M. (1997-1998). Lugo en los tiempos oscuros. Las menciones literarias de la ciudad entre los siglos V y X (III). Boletín do Museo Provincial de Lugo, 8(2), 177-194.

Novo Guisán, J. M. (1999-2000). Lugo en los tiempos oscuros. Las menciones literarias de la ciudad entre los siglos V y X (IV), (V). Boletin do Museo Provincial de Lugo, 9, 219-230.

Núñez García, Ó. (2013). Cristianismo, sociedad y poder: origen y evolución de la jerarquía eclesiástica en la Gallaecia antigua. Hispania Sacra, 65, Extra II, 7-31. DOI: https://doi. org/10.3989/hs.2013.034

Orlandis, J. (1976). Los problemas canónicos de la conversión de los visigodos al catolicismo. En La Iglesia en la España visigótica y medieval (pp. 33-58). Pamplona: Ediciones Universidad de Navarra.

Osland, D. (2011). Tribute and Coinage in the Visigothic Kingdom: On the Role of the Bishop. Anas, 24, 71-95.

Pachá, P. (2019). To Name and Control. Space and Power in the Integration Process of the Visigothic Kingdom of Toledo. Mélanges de la Casa de Velázquez, 49(2), 109-131. DOI: https://doi.org/10.4000/mcv.11081

Pliego, R. (2009). La moneda visigoda, I. Sevilla: Universidad de Sevilla.

Pliego, R. (2012). Gallaecia en tiempos del Reino Visigodo de Toledo: sus emisiones monetarias. En F. Cebreiro Ares
(Ed.). Introducción a la historia monetaria de Galicia (65104). A Coruña: Labirinto de Paixón.

Poveda Arias, P. (2017). A vueltas con la frontera tardoantigua: la Submeseta Norte en los confines del reino visigodo. Arkeogazte, 7, 79-96.

Poveda Arias, P. (2019). La diócesis episcopal en la Hispania visigoda: concepción, construcción y disputas por su territorio. Hispania Sacra, 71(143), 9-24. DOI: https://doi. org/10.3989/hs.2019.001

Poveda Arias, P. (2020). ¿Hacia la unidad de Hispania? Explicaciones sociales a las ofensivas militares visigodas en la península ibérica (siglos VI-VIII). Gladius, 40, 73-92. DOI: https://doi.org/10.3989/gladius.2020.03

Poveda Arias, P. (2021). The Role of the Military Factor in the Political and Administrative Shaping of the Visigothic Kingdom (Sixth to Seventh Centuries). En E. Bennet, G. M. Berndt, S. Esders y L. Sarti (Eds.). Early Medieval Militarisation (pp. 115-129). Manchester: Manchester University Press.

Reinhart, W. (1944-1945). El rey Leovigildo, unificador nacional. Boletín del Seminario de Estudios de Arte y Arqueología, 11, 97-107.

Retamero, F. (2001). Panes et siliquae. Las condiciones de la producción de moneda en el Regnum Gothorum. En J. Arce y P. Delogu (Eds.). Visigoti e Longobardi (pp. 117-132). Firenze: Edizioni All'Insegna del Giglio.

Retamero, F. (2011). La moneda en el Regnum Gothorum (ca. 574-714). Una revisión del registro numismático. En P. C. Díaz e I. Martín Viso (Eds.). Entre el impuesto y la renta. Problemas de la fiscalidad tardoantigua y altomedieval (pp. 189-220). Bari: Edipuglia.

Reuter, T. (1985). Plunder and Tribute in the Carolingian Empire. Transactions of the Royal Historical Society, Fifth Series, 35, 75-94. DOI: https://doi.org/10.1017/ s0080440100017710

Reydellet, M. (1981). La royauté dans la littérature latine de Sidoine Apollinaire à Isidore de Séville. Roma: École Française de Rome.

Rus Rufino, S. (2015): Unidad y paz en el reino visigodo. Dos aspectos del pensamiento político de Isidoro de Sevilla. Antiquité Tardive, 23, 81-94. DOI: https://doi.org/10.1484/j. at.5.109370

Saitta, B. (1979). Un momento di disgregazione nel regno visigoto di Spagna: la rivolta di Ermenegildo. Quaderni Catanesi di Studi Classici e Medievali, 1, 81-134.

Salinero-Sánchez, I. (2020). La Lusitania tardoantigua en el contexto del exilio. En M. F. Palma y V. Lopes (Eds.). $O$ territorio e a gestão dos recursos entre a Antiguidade tardia e o período islámico (pp. 83-95). Granada: Alhulia.

Sánchez Pardo, J. C. (2014). Sobre las bases económicas de las aristocracias en la Gallaecia suevo-visigoda (ca. 530650 D.C.). Comercio, minería y articulación fiscal. Anuario 
de Estudios Medievales, 44(2), 983-1023. DOI: https://doi org/10.3989/hs.2014.058

Sarti, L. (2018). Methoden, Bedeutung und Legitimation der Aneignung von fremdem Eigentum von der Spätantike zum frühen Mittelalter - Zusammenfassung und Diskussion. En R. Keller y L. Sarti (Eds.). Pillages, tributs, captifs : Prédation et sociétés de l'Antiquité tardive au haut Moyen Âge (pp. 179-193). Paris: Éditions de la Sorbonne. DOI: https://doi. org/10.4000/books.psorbonne.39990

Sayas Abengochea, J. J. (1988). La búsqueda visigoda de la unidad territorial y el caso vascónico. Veleia, 5, 189-206.

Schmidt, H.-J. (2003). Le roi et son trésor. Fonction de la puissance royale pendant le haut Moyen Âge. Thesis. Cahier d'histoire des collections, 2, 5-25.

Thompson, E. A. (1980). The Conversion of the Spanish Suevi to Catholicism. En E. James (Ed.). Visigothic Spain. New Approaches (pp. 77-92). Oxford: Clarendon Press.

Thompson, E. A. (2011 [1969]). Los godos en España. Madrid: Alianza Editorial.

Torres, C. 1949. Límites geográficos de Galicia en los siglos IV y V. Cuadernos de Estudios Gallegos, 14, 367-383.
Ubric Rabaneda, P. (2015). The Church in the Suevic Kingdom (411-585 AD). En J. D'Emilio (Ed.). Culture and Society in Medieval Galicia: A Cultural Crossroads at the Edge of Europe (pp. 210-245). Leiden: Brill. DOI: https:// doi.org/10.1163/9789004288607_007

Vallejo Girvés, M. (2003). Los exilios de católicos y arrianos bajo Leovigildo y Recaredo. Hispania Sacra, 55, 35-47. DOI: https://doi.org/10.3989/hs.2003.v55.1111.166

Vallejo Girvés, M. (2012). Hispania y Bizancio. Una relación desconocida. Madrid: Akal.

Velázquez, I. (2000). Zonas y problemas eclesiásticos durante la época de la presencia bizantina en Hispania (una reflexión sobre los textos). En J. M. Gurt y N. Tena (Eds.). V Reunió d'Arqueologia cristiana hispánica - V Reunión de Arqueología cristiana hispánica (pp. 585-599). Barcelona: Institut d'Estudis Catalans.

Velázquez, I. (2003). Pro patriae gentisque Gothorum statu ( $4^{\text {th }}$ Council of Toledo, Canon 75, a. 633). En H.-W. Goetz y J. Jarnut (Eds.). The Relationship between Late Antique and Early Medieval Peoples and Kingdoms in the Transformation of the Roman World (pp. 161-217). Leiden: Brill.

Wood, J. (2012). The Politics of Identity in Visigothic Spain: Religion and Power in the Histories of Isidore of Seville. Leiden: Brill. DOI: https://doi.org/10.1163/9789004224322 
